\title{
Article \\ Mechanical Properties of Selected Epoxy Adhesive and Adhesive Joints of Steel Sheets
}

\author{
Anna Rudawska (D)
}

check for updates

Citation: Rudawska, A. Mechanical Properties of Selected Epoxy

Adhesive and Adhesive Joints of Steel Sheets. Appl. Mech. 2021, 2, 108-126. https://doi.org/10.3390/ applmech 2010007

Received: 19 January 2021

Accepted: 25 February 2021

Published: 3 March 2021

Publisher's Note: MDPI stays neutral with regard to jurisdictional claims in published maps and institutional affiliations.
Faculty of Mechanical Engineering, Lublin University of Technology, Nadbystrzycka 36 St., 20-618 Lublin, Poland; a.rudawska@pollub.pl; Tel.: +48-81-53-84-232

\begin{abstract}
The article presents the issues of the mechanical properties of epoxy adhesives and the adhesive joints strength of steel sheets which were made using the epoxy adhesives. The aim of the paper is to study the mechanical properties of epoxy adhesive of different epoxy resin/curing agent ratios (within and above the recommended stoichiometric ratio) and their effect on mechanical properties of adhesive joints of steel sheets. In experimental tests three types of epoxy adhesives, containing a low molecular weight epoxy resin based on bisphenol A and polyamide curing agent, were used. A single-lap adhesive joint type of stainless-steel sheets was also applied. Two types of strength test were used: the compressive strength tests (DIN EN 196-1) for epoxy adhesive samples and the shear strength tests (DIN EN 1465) for adhesive joints. Both the analysis of the strength results of the samples of epoxy adhesive and adhesive joints as well as the failure analysis was carried out. On the basis of the results of strength tests it can be stated that the greatest deformation occurred for the samples of epoxy adhesive containing the modified epoxy resin (epoxy number-0.40) and the polyamide curing agent, and the smallest for the samples of epoxy adhesive containing the basic epoxy resin (epoxy number-0.49-0.52) and the polyamide curing agent. The epoxy adhesives with a smaller amount of curing agent were characterized by higher strength. This applies to all analyzed epoxy resins. The same dependences were obtained for the strength of adhesive joints of steel sheets made of the analyzed epoxy adhesive.
\end{abstract}

Keywords: mechanical properties; epoxy adhesive compound; adhesive joint

\section{Introduction}

Adhesive joints are classified as non-detachable bonded joints. Adhesives are used not only to joint elements, but often the use of adhesive is to seal various elements, e.g., threaded joints. Adhesives are also used for regeneration and repair, among others to remove leaks in gas pipes or to remove leaks in various tanks. Obtaining adhesive joints of adequate strength in given operating conditions requires a series of tests. It depends, inter alia, on the properties of the adhesive used to make the joints [1-4]. Due to their favorable properties and high processing possibilities, epoxy resins are increasingly being used in various industries and many applications [5-11]. Their polar nature determines very good adhesion of epoxy resins to many materials $[6,12,13]$. Epoxy resins, thanks to their characteristic properties, are included in the group of the best adhesive materials [12]. Epoxy adhesives are characterized by better properties than most other adhesives due to very good adhesion and chemical resistance [14,15]. A large variety of resins and curing agents, as well as the possibility of modifying the properties of epoxy adhesives allow for the selection of the most appropriate composition for the joined material and the operating conditions $[9,12,16-18]$. One of the possibilities of obtaining epoxy adhesives with specific properties is the selection of both the type of epoxy resin and the type of curing agent [11,19-21]. For example, it is possible to obtain adhesives that are less or more flexible or resistant to various external factors [22,23]. The use of the appropriate curing agent allows for joining together moist materials or joining at low temperatures [18]. 
Curing agents usually react with epoxy resins in stoichiometric ratios $[6,7,21]$. The stoichiometric ratio is the quantitative ratio of the reactants in a chemical reaction (molar, mass, volume). Therefore, it is important to observe the recommended stoichiometric ratios when preparing epoxy adhesives, a very large group of which are two-component adhesives: resin and curing agent, as it affects the mechanical properties of the cured adhesive, including the adhesive layer in adhesive joints. In the stoichiometry of an epoxy/curing agent system, for each end group of an epoxy molecule, there is a corresponding hydrogen atom attached to the nitrogen for amine-based curing agent \{20].

Some researchers investigated the epoxy resin/curing agent system in various ratios in various aspects [24-28]. Saleh et al. [25] investigated the mechanical properties of epoxy resin based on bisphenol A (DGEBA) cured with different curing agents: triethylenetetramine (TETA) and diaminodiphenylmethane (DDM). The epoxy compounds were prepared for different resin/curing agent ratios, e.g., under stoichiometry, stoichiometry and above stoichiometry). On the basis of the obtained results, it was found that the analyzed epoxy resin and hardeners systems, in which a higher stoichiometric ratio of these substances were used, allowed to obtain the best mechanical properties. d'Almeida and Monteiro [26] also considered various epoxy resin/curing agent ratios in their tests. They studied epoxy resin based on bisphenol A (DGEBA) cured with a triethylenetetramine (TETA). The epoxy resin/curing agent ratio used varied between 7 and 21 parts of the curing agent per 100 parts of epoxy resin, phr and eight resin formulations were prepared. In turn Vanlandingham et al. [27] investigated the changes in microstructure and mechanical properties as a function of epoxy-amine system stoichiometry. They noticed that the fracture toughness at room temperature increases with the increasing amine content, most likely due to the increased presence of the soft phase, which absorbs more energy during crack growth.

The strength of cured resins is significantly affected by the chemical composition of the curing agent $[7,13,20,28-34]$. In order to obtain products with high strength properties, i.e., with a rigid structure and high cross-linking density, it is necessary to use curing agents which consist of many functional groups and contain aromatic rings. The relative content of the curing agent with respect to the stoichiometric compositions affects the rigidity, strength, and the deformability of an epoxy network [34]. Saleh et al. [25] also underlined that the properties of epoxy resin/ curing agent system depend on the type of the curing agent used and the stoichiometric ratio of the resin and curing agent mentioned above. The authors [25] presented that the DGEBA/DDM epoxy system shows a higher impact strength than the DGEBA/TETA epoxy system and this is because aliphatic amines (e.g., TETA) as curing agents are less stable than aromatic amines (of which DDM curing agent is an example). Liu et al. [19] also investigated e.g., the effects of curing agents, curing temperature and ratio of epoxy resin and epoxidized soybean oil and they emphasized the influence of the type of hardener on the mechanical properties of epoxy composites. d'Almeida and Monteiro in work [26] underlined that the mechanical, physical and chemical properties of the polymer matrix (epoxy resin) can be prepared e.g., by changing the type and the amount of the chemical substance used as the curing agent. Ozgul and Ozkul [20] confirmed that the type, amount and functionality of the curing agent, as well as the curing conditions, affects the properties of the cured epoxy resin.

Epoxy adhesives are used in many areas for joining various materials, and they are used for joining both the same materials and different ones [6,15,23,35-37]. The effectiveness of the bonding process depends on both the selection of the appropriate type of adhesive and the proper preparation of the surfaces of the joined materials, as well as the correct development of the entire technological process of bonding [5,35,38,39].

The aim of the paper is to study the mechanical properties of epoxy adhesives of different epoxy resin/curing agent ratios and their effect on mechanical properties of adhesive joints of steel sheets. In the article the amount of resin and curing agent was used within and above the recommended stoichiometric ratio. The quantitative ratio of elements (stoichiometric ratio) in a chemical compound by mass was used in the study. 
An attempt was made to determine whether the amount of the curing agent in the epoxy adhesive compounds containing epoxy resin and polyamide curing agent (in terms of the stoichiometric ratio and above the stoichiometric ratio), it significantly affects the mechanical properties of both the epoxy compounds themselves and the adhesive joints made with these epoxy adhesives.

\section{Materials and Methods}

The research consisted of two stages: the first one concerned the analysis of the mechanical properties of epoxy adhesives, while the second one covered the strength tests of the adhesive joints of steel sheets made of the adhesives analyzed in the first stage.

\subsection{Epoxy Adhesives}

Three types of epoxy adhesives containing the low molecular weight epoxy resins based on bisphenol A (Table 1) and polyamide curing agent with an amine number between 290 and $360 \mathrm{mg} \mathrm{KOH} / \mathrm{g}$ (PAC trade name) were used to prepare the adhesive samples. Three types of epoxy resins were used: Epidian 5 (trade name) unmodified base resin and two modified epoxy resins: Epidian 53 and Epidian 57 (trade names). The basis of modified resins is the Epidian 5 base resin. The average molecular weight of the unmodified base epoxy resin (Epidian 5-trade name) used is approx. $400 \mathrm{~g} / \mathrm{mol}$. All these resins are used to produce epoxy adhesives, but they have different physicochemical and functional properties. The resins and polyamide curing agent are produced by CIECH Resins manufacturer, Nowa Sarzyna, Poland.

Table 1. Selected properties of tested epoxy resins [40].

\begin{tabular}{cccc}
\hline \multirow{2}{*}{ Properties } & \multicolumn{3}{c}{ Epoxy Resin Type (Trade Names) } \\
\cline { 2 - 4 } & Epidian 5 & Epidian 53 & Epidian 57 \\
\hline Viscosity $(\mathrm{mPas})$ at $25^{\circ} \mathrm{C}$ & max. 30,000 & $900-1500$ & $13,000-19,000$ \\
Density $\left(\mathrm{g} / \mathrm{cm}^{3}\right)$ at $20^{\circ} \mathrm{C}$ & 1.17 & $1.11-1.15$ & $1.14-1.17$ \\
Epoxy number $(\mathrm{mol} / 100 \mathrm{~g})$ & $0.49-0.52$ & 0.41 & 0.40 \\
\hline
\end{tabular}

The amount of resin and curing agent was used within and above the recommended stoichiometric ratio. The quantitative ratio of elements (stoichiometric ratio) in a chemical compound by mass was used in the study. For epoxy resin with an epoxy number of 0.49-0.52 (unmodified resin) and polyamide curing agent with an amine number between 290 and $360 \mathrm{mg} \mathrm{KOH} / \mathrm{g}$, the range of this ratio is 60-100 (amount of curing agent per $100 \mathrm{~g}$ of resin). For other resins it is in the range: respectively for epoxy resin with epoxy number $0.41-50-80 \mathrm{~g}$ of curing agent per $100 \mathrm{~g}$ of resin, and for epoxy resin with epoxy number $0.40-50-80 \mathrm{~g}$ of curing agent per $100 \mathrm{~g}$ of resin.

It was decided that two variants of the epoxy composition were used.

Variant A: for all compositions, the maximum recommended amount (by weight) of polyamide curing agent in the adhesive compounds will be used per $100 \mathrm{~g}$ of resin, i.e., (i) for the resin with an epoxy number of 0.49-0.52 it was the value of $100 \mathrm{~g}$ of polyamide curing agent, (ii) for the second resin (with epoxy number 0.41) and third resin (with epoxy number 0.40 ) it was the value of $80 \mathrm{~g}$ per $100 \mathrm{~g}$ of resin.

Variant B: for two epoxy compositions (containing modified resins) the amount of polyamide curing agent above the stoichiometric ratio was used, i.e., $100 \mathrm{~g}$ polyamide curing agent per 100 epoxy resin. This is the ratio suitable for compounds containing unmodified resin. The designations of the tested epoxy adhesives are given in Tables 2 and 3. 
Table 2. Designations of epoxy adhesives-variant A.

\begin{tabular}{|c|c|c|c|}
\hline Epoxy Resin (Trade Name) & Curing Agent & $\begin{array}{l}\text { Amount of Epoxy Resin/Curing Agent (g), } \\
\text { According to Stoichiometric Ratio }\end{array}$ & Designation \\
\hline & \multirow{4}{*}{ polyamide } & $100 / 100$ & E5/PAC/100:100 \\
\hline Epidian 5 & & $100 / 80$ & E5/PAC/100:80 \\
\hline Epidian 53 & & $100 / 80$ & E53/PAC/100:80 \\
\hline Epidian 53 & & $100 / 80$ & E57/PAC/100:80 \\
\hline
\end{tabular}

Table 3. Designations of epoxy adhesives—variant B.

\begin{tabular}{cccc}
\hline Epoxy Resin (Trade Name) & Curing Agent & $\begin{array}{c}\text { Amount of Epoxy Resin/Curing Agent (g), } \\
\text { Above Stoichiometric Ratio }\end{array}$ & Designation \\
\hline Epidian 53 & polyamide & $100 / 100$ & E53/PAC/100:100 \\
Epidian 57 & & $100 / 100$ & E57/PAC/100:100 \\
\hline
\end{tabular}

\subsection{Epoxy Adhesives Samples Preparation}

For the first stage of strength tests, cylindrical samples of individual types of epoxy adhesive were prepared in the cured state (Table 2). The right amount of the resin and curing agent for each epoxy adhesive were batched with an electronic scale (OX-8100 type, FAWAG S.A, Lublin, Poland, measurement accuracy $0.1 \mathrm{~g}$, ISO 9001) in a polymer container. Then the epoxy adhesive components were mechanically mixed using an anchor stirrer at a speed of 460 RPM for 2 min on a mechanical mixing station. Next the epoxy mixture was kept under vacuum for $2 \mathrm{~min}$. The batching and mixing processes were made at temperature of $22 \pm 2{ }^{\circ} \mathrm{C}$ and $30-32 \% \mathrm{RH}$.

The adhesive mixture was, then, placed in cylindrical polypropylene molds after being mixed in the liquid state. The polypropylene molds' internal surface was sprayed with an anti-adhesive silicone agent (SOUDAL Joint Finish, Soudal NV, Tornhout, Belgium), for $10 \mathrm{~s}$ from a distance of 25-30 mm. Dimensions of cylindrical cured adhesive samples are shown in Figure 1.

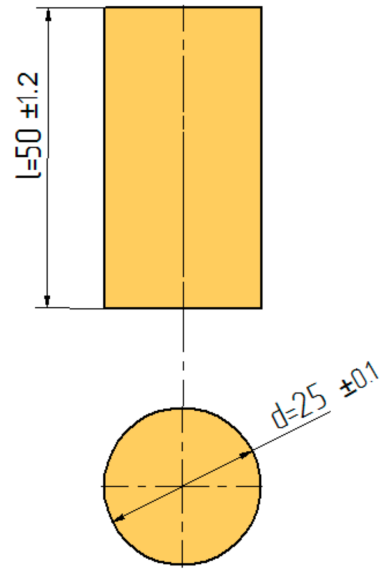

(a)



(b)

Figure 1. Sample of cured epoxy adhesives samples as: (a) dimension; (b) real view of E5/PAC/100:100 sample.

The curing was realized as a one-step cold curing. The curing process was performed at the temperature of: $22 \pm 1{ }^{\circ} \mathrm{C}$, at the humidity of $22 \pm 1 \%$ for 7 days. Six samples were made for each epoxy adhesive hence the total number of samples was 36 (6 types of adhesive-Table $2 \times 6$ samples). 


\subsection{Adhesive Joints}

The adhesive joints are made of non-alloy structural steel sheets with the designation C45 (C45/1.0503, PN/EN 10083-2). The selected mechanical properties of this steel are presented in Table 4.

Table 4. Mechanical properties of C45 steel sheet (PN/EN 10083-2).

\begin{tabular}{ccc}
\hline Mechanical Properties & Designation & Value \\
\hline Tensile strength $(\mathrm{MPa})$ & $\mathrm{R}_{\mathrm{m}}$ & $650-800$ \\
Yield point $(\mathrm{MPa})$ & $\mathrm{R}_{\mathrm{e}}$ & 430 \\
Elongation at break $(\%)$ & $\mathrm{A}$ & 19 \\
Hardness $(\mathrm{HB})$ & $\mathrm{HB}$ & 250 \\
\hline
\end{tabular}

For bonding, samples made of C45 steel sheet $2( \pm 0.2)$ mm thickness, $100( \pm 1.3) \mathrm{mm}$ length and $25( \pm 0.8) \mathrm{mm}$ width were used. The shape and dimensions of the tested samples are shown in Figure 2.

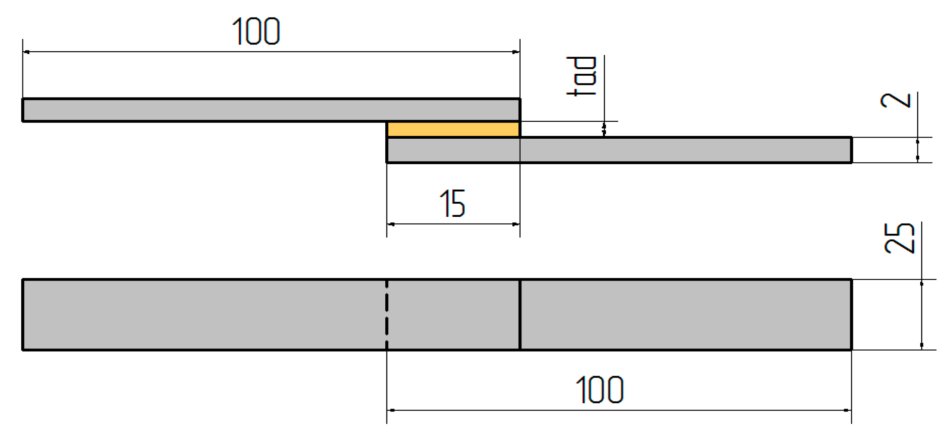

Figure 2. Scheme of single-lap bonded joints (theoretical dimensions in $\mathrm{mm}$ ).

The overlap length of the adhesive joints was assumed to be $15 \mathrm{~mm}$, while after the joints were made, the range of the obtained lengths was: $15.44( \pm 0.86) \mathrm{mm}$ to $17.29( \pm 0.55) \mathrm{mm}$ ). The obtained dimensions of the adhesive layer in adhesive joints (mean values) after the curing process are given in Table 5.

Table 5. Dimensions of adhesive layer in adhesive joints (after epoxy adhesive curing).

\begin{tabular}{ccc}
\hline \multirow{2}{*}{ Epoxy Adhesive Designation } & \multicolumn{2}{c}{ Dimensions of Adhesive Layer (mm) } \\
\cline { 2 - 3 } & Overlap Length & $\begin{array}{c}\text { Thickness of Adhesive Layer } \\
\text { (Tad-Figure } 1)\end{array}$ \\
\hline E5/PAC/100:100 & $15.44( \pm 0.86)$ & $0.38( \pm 0.11)$ \\
E5/PAC/100:80 & $16.75( \pm 0.78)$ & $0.52( \pm 0.10)$ \\
\hline E53/PAC/100:100 & $15.99( \pm 0.62)$ & $0.32( \pm 0.05)$ \\
E53/PAC/100:80 & $17.29( \pm 0.55)$ & $0.53( \pm 0.18)$ \\
\hline E57/PAC/100:100 & $17.04( \pm 0.90)$ & $0.30( \pm 0.04)$ \\
E57/PAC/100:80 & $16.69( \pm 0.82)$ & $0.49( \pm 0.08)$ \\
\hline
\end{tabular}

In order to prepare the surface for the bonding process, mechanical treatment and surface degreasing were used. The machining was performed using P800 sandpaper (RS Components, Warsaw, Poland), with 30 circular movements on each sample. LOCTITE ${ }^{\circledR}$ SF $7063^{\mathrm{TM}}$ degreasing agent (Loctite, Henkel Europe, Düsseldorf, Germany) was used to degrease the surface after mechanical treatment. Degreasing by spraying was performed in several steps: (i) application of the degreasing agent by spraying over the adherend's surface, (ii) wiping off the wet surfaces with dust-free pads to remove impurities, (iii) the above actions were repeated twice; (iv) in the final step, the degreasing agent was left to 
evaporate (approximately $2 \mathrm{~min}$ ). The degreasing process was carried out at a temperature of $22 \pm 2{ }^{\circ} \mathrm{C}$ and $30-32 \% \mathrm{RH}$. After the surface of the samples was prepared, the joining process was started at a temperature of $22 \pm 2{ }^{\circ} \mathrm{C}$ and $30-32 \%$ RH with the use of six types of adhesives presented in Tables 2 and 3. The same conditions for applying the adhesive, dimensioning and exerting the same pressure during curing were ensured when making the adhesive joints. The same amount of adhesive was applied by spatula to the one surface of the joined elements and the same amount of pressure was applied to the complex and fixed elements of the joints. For this purpose, an appropriate fixing device was used, allowing the execution of 1 batch of samples of adhesive joints, including 10 joints, simultaneously. Surface pressure was applied to the entire joining area and the pressure value was $0.018 \mathrm{MPa}$.

Curing was carried out in cold one-step at ambient temperature $\left(22 \pm 2{ }^{\circ} \mathrm{C}\right)$ and $30-32 \% \mathrm{RH}$, during 7 days. Six series of adhesive joints were made, 10 samples each. The total number of samples of adhesive joints was 60 samples. An exemplary adhesive joint after curing is shown in Figure 3.

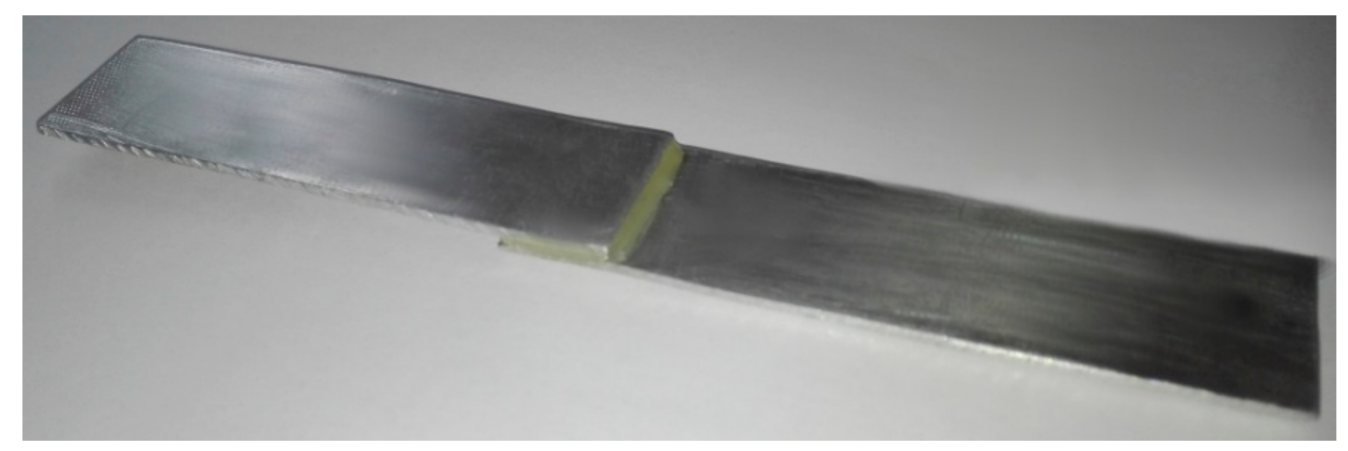

Figure 3. Example of single-lap bonded joints.

\subsection{Tests Characteristics}

\subsubsection{Mechanical Tests}

After the curing process, the epoxy adhesive samples were tested for compressive strength in accordance with DIN EN 196-1, on the Zwick/Roell 150 testing machine (ZwickRoell GmbH\&Co. KG, Ulm, Germany). During the strength test, the initial force was $10 \mathrm{~N}$, the traverse speed was $10 \mathrm{~mm} / \mathrm{min}$, and the maximum deformation was set at $15 \%$.

Six series of adhesive joints (the series of joint was 10 samples) were subjected to shear strength tests (in accordance with DIN EN 1465) on the Zwick/Roell Z150 testing machine (ZwickRoell GmbH\&Co. KG, Ulm, Germany). The test speed was $5 \mathrm{~mm} / \mathrm{min}$.

Both strength tests of adhesives and adhesive joints were carried out at ambient temperature $\left(22 \pm 2{ }^{\circ} \mathrm{C}\right)$ and humidity of $28-30 \% \mathrm{RH}$. During the compressive strength tests of epoxy adhesive samples, the following mechanical properties were determined: compressive strength and compressive strain. During the shear strength tests of the adhesive joints' samples, the following mechanical properties were determined: shear strength, shear modulus, and elongation at break.

\subsubsection{Surface Roughness Parameters Measurement}

After the surface was prepared for bonding, the following surface roughness parameters were measured: 
- Rmax-maximum roughness height;

- $\mathrm{Ra}$-arithmetic mean of roughness profile deviation;

- $\mathrm{Rz}$-the highest roughness profile height;

- Rsm-average roughness spacing on the elementary section.

Designation of surface roughness parameters complies with the standard PN-EN ISO 4287. These measurements were carried out in order to characterize the surface of the joined material after the surface preparation process for the bonding process.

The Hommel Tester T1000 contact profilometer (Hommelwerke GmbH, Schwenningen, Germany) was used to measure the surface roughness parameters. The sampling length was $0.08 \mathrm{~mm}$.

\section{Results}

\subsection{Epoxy Adhesives-Compressive Test}

The comparison of the results of the compressive strength of cylindrical epoxy adhesives samples is presented in Figures 4 and 5.

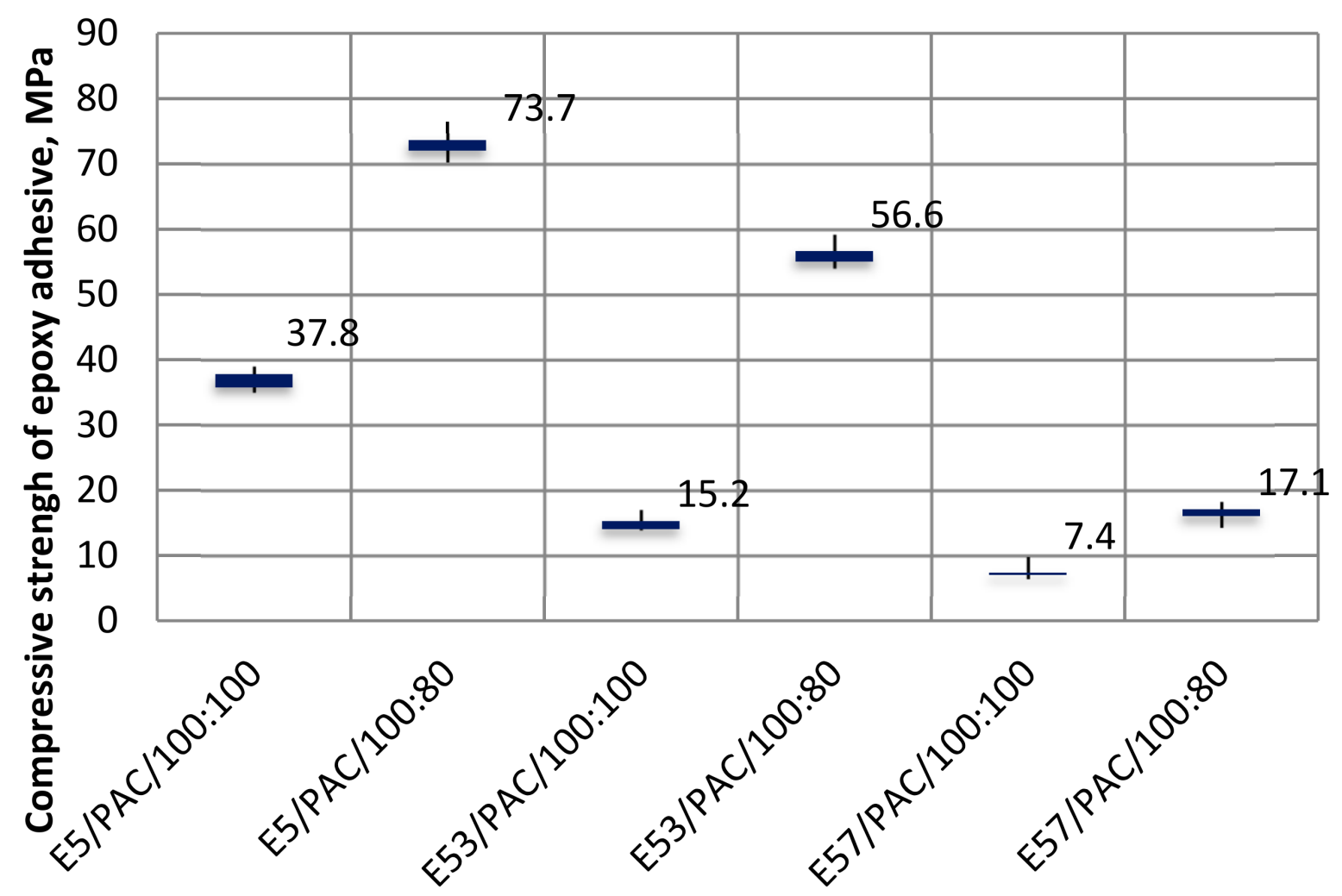

Type of epoxy adhesive

Figure 4. Compressive strength of epoxy adhesives. 


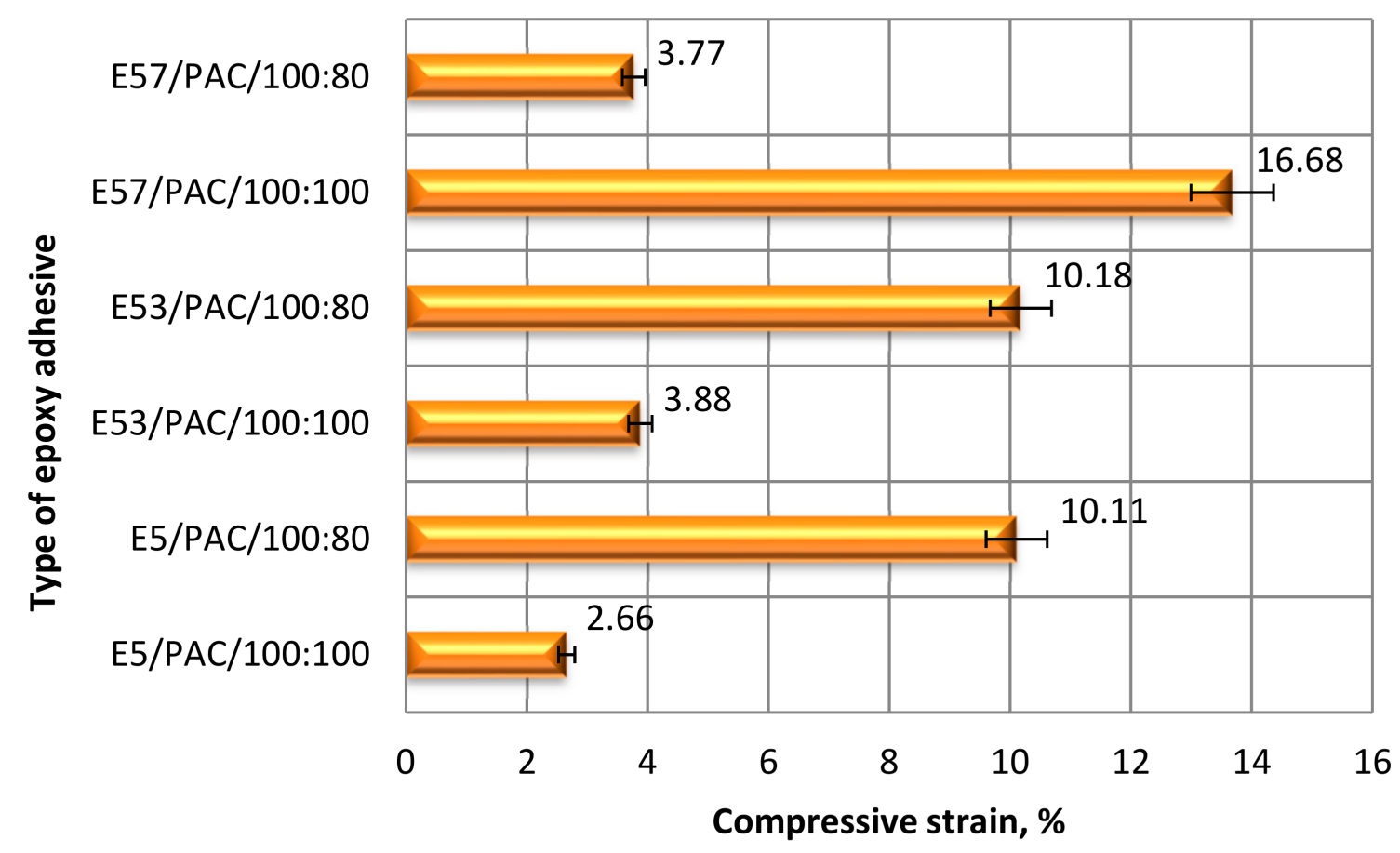

Figure 5. Compressive strain of epoxy adhesives.

The comparison of the epoxy adhesive compressive strength results after curing was made on the basis of the following criteria presented in the Table 6.

Table 6. Comparative criteria.

\begin{tabular}{|c|c|c|c|c|}
\hline \multicolumn{2}{|c|}{ Comparative Criteria } & \multicolumn{3}{|c|}{ Epoxy Adhesives Compared } \\
\hline Criterion Designation & Criterion Description & Adhesive 1 & Adhesive 2 & Adhesive 3 \\
\hline $\mathrm{C} 1$ & $\begin{array}{l}\text { The maximum } \\
\text { recommended amount (by } \\
\text { weight) of polyamide curing } \\
\text { agent in the adhesive } \\
\text { compounds per } 100 \mathrm{~g} \text { of resin }\end{array}$ & E5/PAC/100:100 & E53/PAC/100:80 & E57/PAC/100:80 \\
\hline $\mathrm{C} 2$ & $\begin{array}{l}100 \mathrm{~g} \text { of polyamide curing } \\
\text { agent in the adhesive } \\
\text { compounds per } 100 \mathrm{~g} \text { of } \\
\text { resin (100:100) }\end{array}$ & E5/PAC/100:100 & E53/PAC/100:100 ${ }^{1}$ & $\mathrm{E} 57 / \mathrm{PAC} / 100: 100^{1}$ \\
\hline C3 & $\begin{array}{l}80 \mathrm{~g} \text { of polyamide curing } \\
\text { agent in the adhesive } \\
\text { compounds per } 80 \mathrm{~g} \text { of } \\
\text { resin }(80: 80)\end{array}$ & E5/PAC/100:80 & E53/PAC/100:80 & E57/PAC/100:80 \\
\hline
\end{tabular}

${ }^{1}$ Variant B - the amount of polyamide curing agent is above the stoichiometric ratio curing agent/epoxy resin (point 2.1).

When analyzing the first criterion C1 (Table 6), it was noticed that in the case of epoxy adhesive containing unmodified resin (Epidian 5) and the largest amount of curing agent within the recommended stoichiometric ratios ( $100 \mathrm{~g}$ per $100 \mathrm{~g}$ of resin), lower strength was obtained than in the case of other epoxy adhesive containing modified resins (Epidian 53). The highest strength, considering the epoxy adhesives taking into account the $\mathrm{C} 1$ criterion, was achieved by the E53/PAC/100:80 adhesive- $56.62 \mathrm{MPa}$, and the differences between these adhesives (criterion C1) are, respectively: E53/PAC/100:80 versus E5/PAC/100:100$32 \%$ and $\mathrm{E} 53 / \mathrm{PAC} / 100: 80$ versus $\mathrm{E} 57 / \mathrm{PAC} / 100: 80-70 \%$.

Regarding the second criterion (C2) and the third criterion (C3) in the case of E53/PAC/ 100:80 and E57/PAC/100:80 epoxy adhesives, which contained the highest amount of 
curing agent content in the recommended stoichiometric ratios, a higher value of compressive strength was obtained in comparison to these epoxy adhesives, but containing a polyamide curing agent above the recommended stoichiometric ratio (i.e., $100 \mathrm{~g}$ curing agent per $100 \mathrm{~g}$ epoxy resin). The difference between the compressive strength of the epoxy adhesive with a higher percentage of the polyamide curing agent (100:100), above the stoichiometric ratio, compared to the epoxy adhesive with a lower proportion (100:80) - the largest amount of curing agent within the recommended stoichiometric ratios, is, respectively, 73\% (E53/PAC/100:80 versus E53/PAC/100:100) and 57\% (E57/PAC/100:80 versus E57/PAC/100:100). This means that exceeding the recommended stoichiometric amount of curing agent in the epoxy adhesive causes a significant deterioration of the compressive strength of the analyzed epoxy adhesive compounds.

Considering the results of compressive strength (C2 and C3 criteria-Table 6) in relation to the epoxy adhesive containing the unmodified resin (Epidian 5) in the range of the recommended stoichiometric ratios, the epoxy adhesive with a lower amount of the polyamide curing agent (E5/PAC/100:80) is characterized by a higher compressive strength than the epoxy adhesive with a higher amount of curing agent (maximum amount from the recommended stoichiometric values). The difference is close to $50 \%$. These results imply the need for further research in this area. In general, of all the compared results, the highest strength was obtained for this particular epoxy adhesive (E5/PAC/100:80) and it amounts to $73.67 \mathrm{MPa}$.

Comparing the obtained results of epoxy adhesives compressive strain, taking into account the first criterion $\mathrm{C} 1$ (Table 6), it was noticed that there are different relations. In the case of epoxy adhesive containing unmodified resin (Epidian 5) and the highest amount of curing agent within the recommended stoichiometric ratios (100 g curing agent per $100 \mathrm{~g}$ of resin), smaller compressive strains were obtained than in the case of other epoxy adhesives, i.e., E53/PAC/100:80 and E57/PAC/ 100:80. Taking into account the $\mathrm{C} 1$ criterion, the greatest compressive strain was characteristic of the 53/PAC/100 epoxy adhesive: $10.18 \mathrm{~mm}$ and it was a value greater than that of other epoxy adhesives, respectively by: compared to 5/PAC/100:100 epoxy adhesive- $74 \%$, and compared to 57/PAC/100:80 epoxy adhesive-63\%.

Comparing the $\mathrm{C} 2$ and $\mathrm{C} 3$ criteria, different dependencies of the compressive strain results depending on the type of epoxy adhesive were noticed. The 53/PAC/100:80 epoxy adhesive (with the maximum recommended stoichiometric amount of curing agent (80 g) in relation to $100 \mathrm{~g}$ of this epoxy resin), obtained a higher compressive strain than the adhesive containing the polyamide curing agent in the amount above the recommended stoichiometric amount (i.e., 100:100). The difference is $62 \%$. On the other hand, in the case of epoxy adhesive containing Epidian 57 epoxy resin, the opposite relationship was obtained: epoxy adhesive with curing agent content above the recommended stoichiometric amount (in this case $100 \mathrm{~g}$ of curing agent per $100 \mathrm{~g}$ of resin) obtained a much greater compressive strain value, amounting to $16.68 \mathrm{~mm}$. It is also the highest value of compressive strain among the studied cases. This means that the E57/PAC/100:100 epoxy adhesive is more flexible than the other tested epoxy adhesives. The difference in the compressive strain value between 57/PAC/100:80 and 57/PAC/100:100 epoxy adhesives is 77\%.

Comparing the E5/PAC/100:100 and E5/PAC/100:80 epoxy adhesive samples (in which the amount of curing agent was assumed in the range of recommended amounts), it can be noticed that the compressive strain of the sample with the highest amount of curing agent is four times lower for the equal proportion of the adhesive and the curing agent.

The standard deviation values of the compressive strain for all analyzed epoxy adhesives are comparable and have small values. Individual values oscillate around average values.

The examples of force-strain curves for all types of epoxy adhesives were similar and these curves were shown in Figures 6-11. The force-strain curves of different colors in Figures 6-11 represent the results of the individual epoxy compounds samples in each series. 


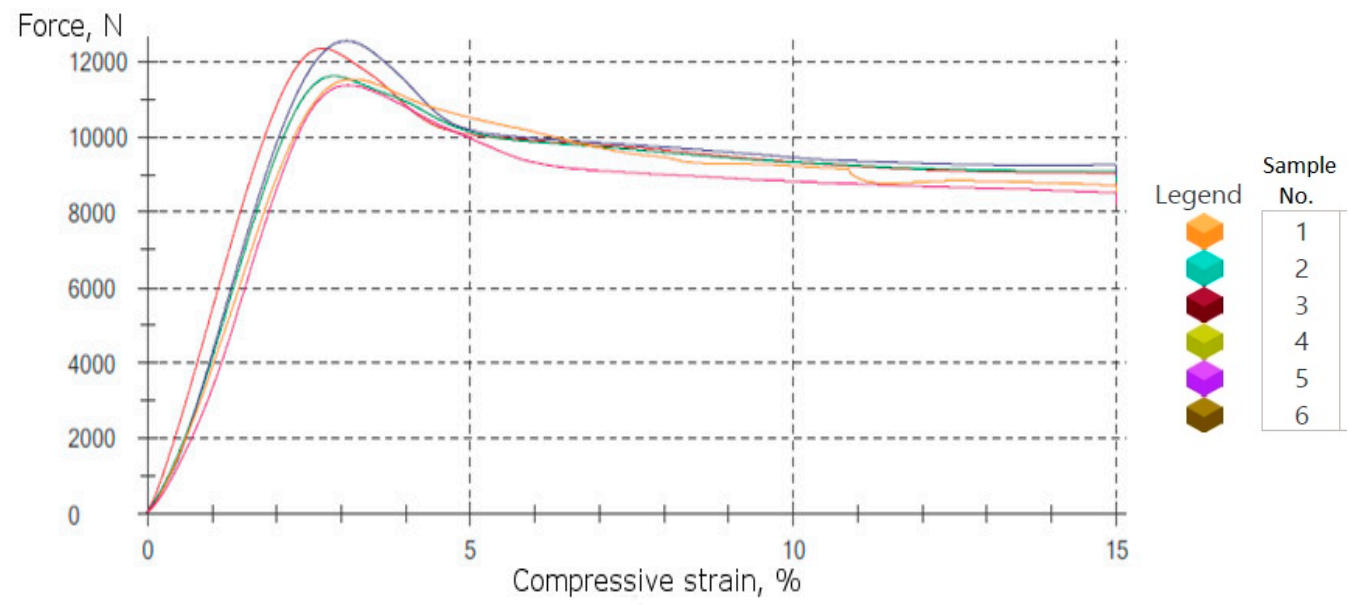

Figure 6. Force-strain curves of the E5/PAC/100:100 epoxy adhesive.

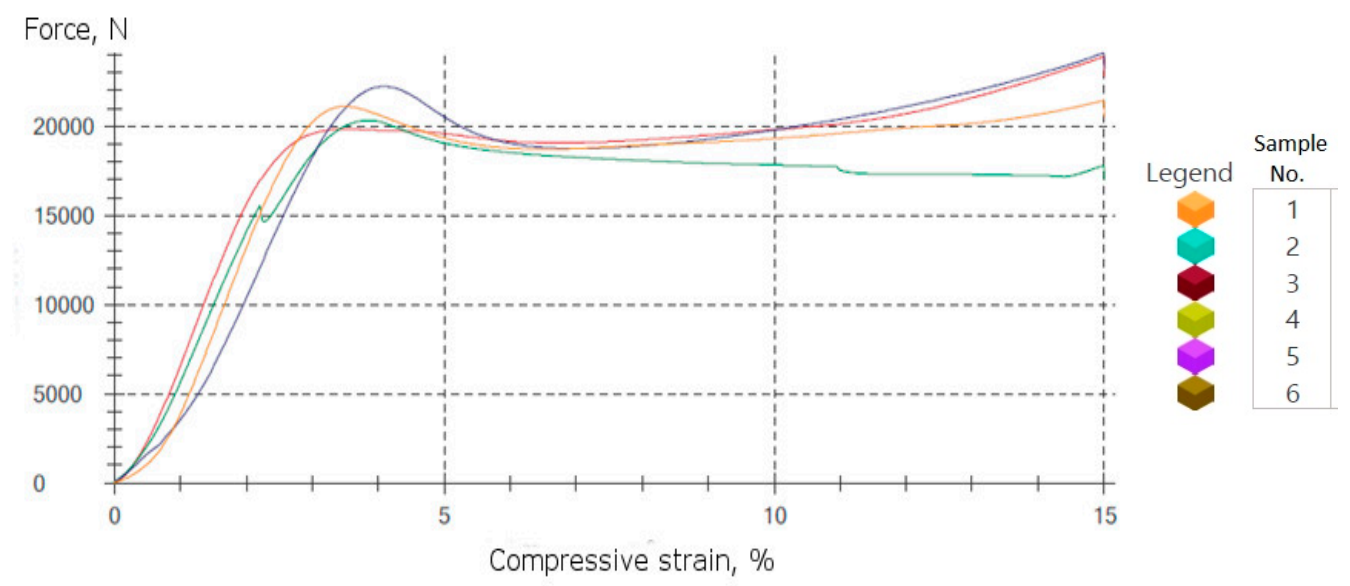

Figure 7. Force-strain curves of the E5/PAC/100:80 epoxy adhesive.
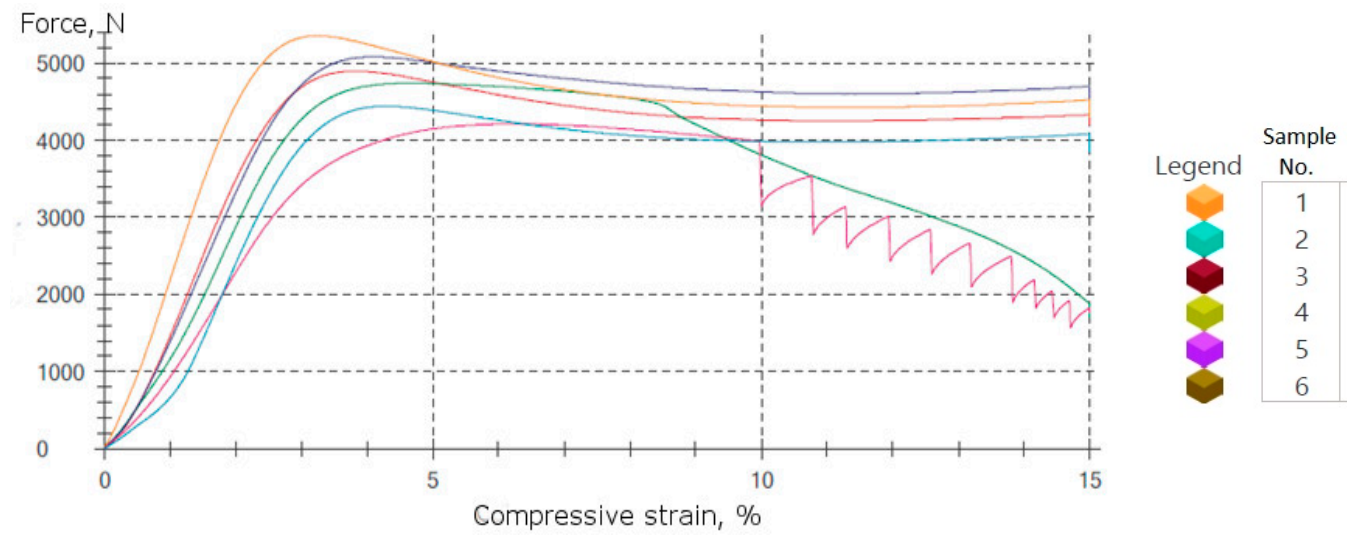

Figure 8. Force-strain curves of the E53/PAC/100:100 epoxy adhesive. 


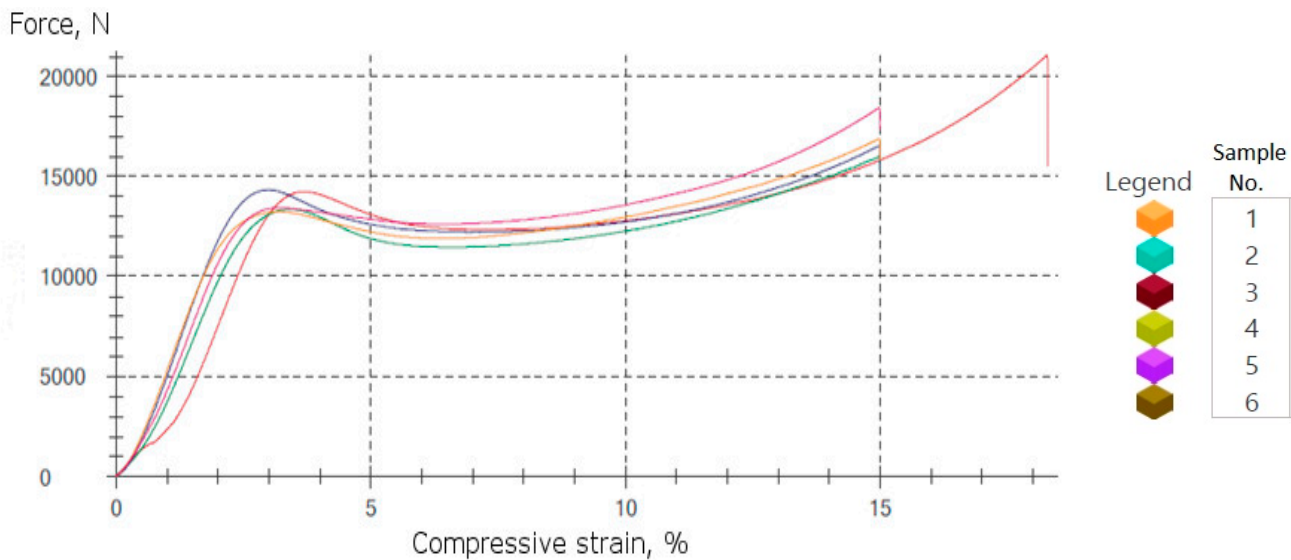

Figure 9. Force-strain curves of the E53/PAC/100:80 epoxy adhesive.

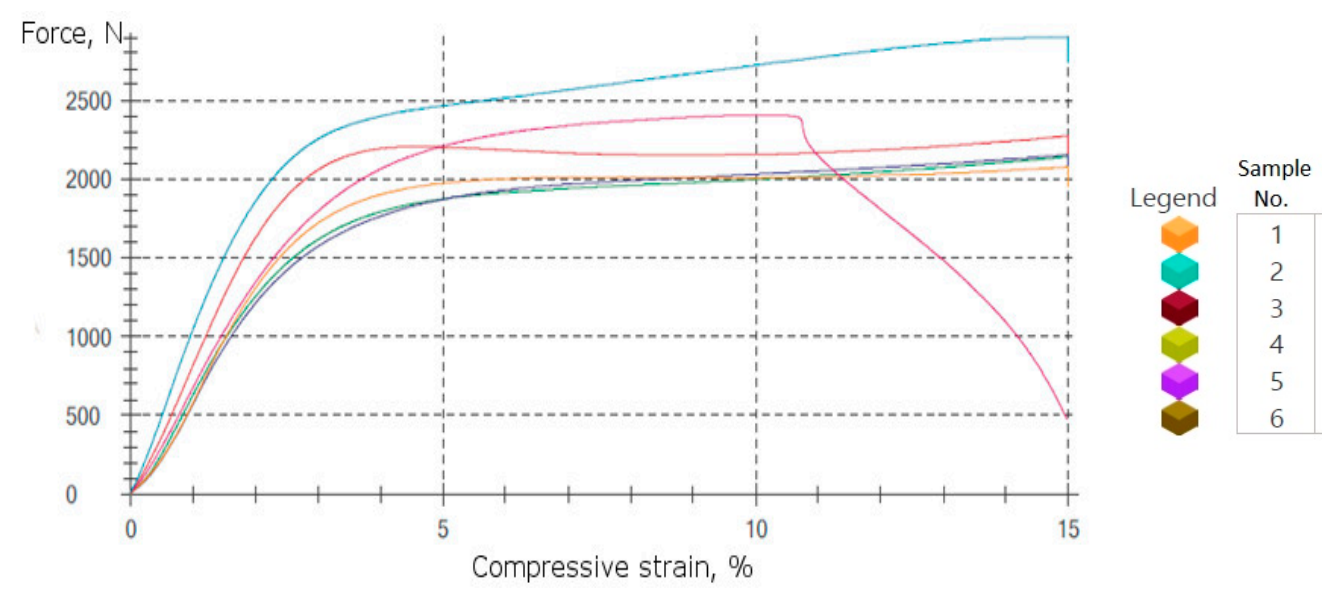

Figure 10. Force-strain curves of the E57/PAC/100:100 epoxy adhesive.

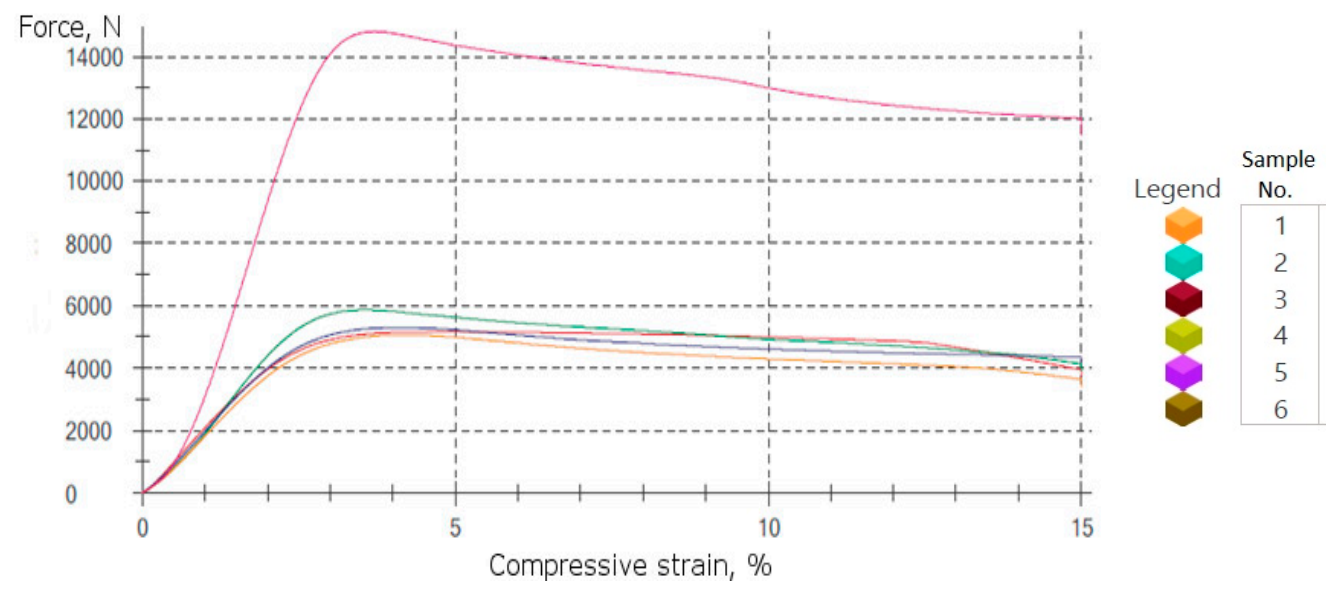

Figure 11. Force-strain curves of the E57/PAC/100:80 epoxy adhesive.

Comparing the compressive strain curves (Figures 6-11) for the analyzed types of epoxy adhesive, it is noted that, in most cases, the analyzed epoxy adhesives (after curing) are materials of reduced stiffness, exhibiting some of the characteristics of ductile materials. In the case of epoxy adhesive containing the Epidian 57 epoxy resin, a slightly different nature of the force-strain curve was observed, but it is still a characteristic curve for polymeric materials showing the characteristics of ductile materials, not the brittle ones.

Exemplary samples of the adhesive after the compressive strength test are shown in Figure 12 . When visually assessing the deformation, it was noticed that after exceeding 
the elastic limit, permanent deformations appear in the sample. The sample swelled to a barrel shape.
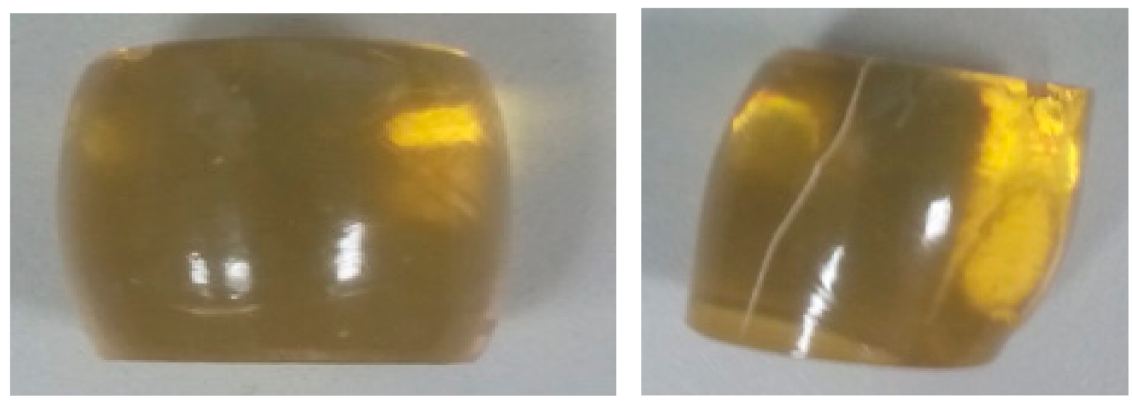

Figure 12. View of E53/PAC/100:80 epoxy adhesives sample after compressive strength test [41].

\subsection{Adhesive Joints}

\subsubsection{Surface Roughness of Adherend}

The results of measurements of the surface roughness parameters of the joined sheet after machining are presented in Table 7.

Table 7. Surface roughness parameters of adherends surface.

\begin{tabular}{ccccc}
\hline \multirow{2}{*}{ Sample } & \multicolumn{4}{c}{ Surface Roughness Parameters ${ }^{\mathbf{1}}(\boldsymbol{\mu m})$} \\
\cline { 2 - 5 } & $\mathbf{R a}$ & $\mathbf{R z}$ & $\mathbf{R s m}$ & $\mathbf{R m a x}$ \\
\hline 1 & 1.95 & 10.90 & 0.21 & 12.76 \\
2 & 1.81 & 10.50 & 0.21 & 12.07 \\
3 & 1.92 & 10.67 & 0.20 & 12.42 \\
4 & 1.93 & 10.11 & 0.21 & 11.99 \\
\hline Mean & 1.90 & 10.55 & 0.21 & 0.35 \\
Standard & 0.06 & 0.33 & 0.01 & \\
deviation & & & & \\
\hline
\end{tabular}

${ }^{1}$ These are the mean values of 10 measurements for each of four randomly selected sample.

Roughness measurements were aimed at determining the roughness parameters and showing the appropriate surface development. The performed mechanical treatment allowed to obtain the 6th accuracy class, which has a positive effect on the adhesive forces occurring between the tested material and the adhesives used.

The Rz parameter value for each profile was very similar (from 10.11 to $10.90 \mu \mathrm{m}$ ). All values of the measured roughness parameters for each of the four tested samples of steel sheets are characterized by a very small dispersion (they are similar to each other).

\subsubsection{Shear Test of Adhesive Joints}

The shear strength of adhesive joints (mean value with standard deviation), depending on the epoxy adhesive used, is shown in Figure 13.

Based on the results of strength tests of adhesive joints (Figure 13), made with the variants of epoxy adhesive containing the largest amount of curing agent within the recommended stoichiometric ratios, e.g., E5/PAC/100:100, E53/PAC/100:80 and E57/PAC/100:80 epoxy adhesives ( $\mathrm{C} 1$ criterion-Table 5) it can be noticed that the shear strength is the highest in particular groups of adhesives containing the same type of components. 


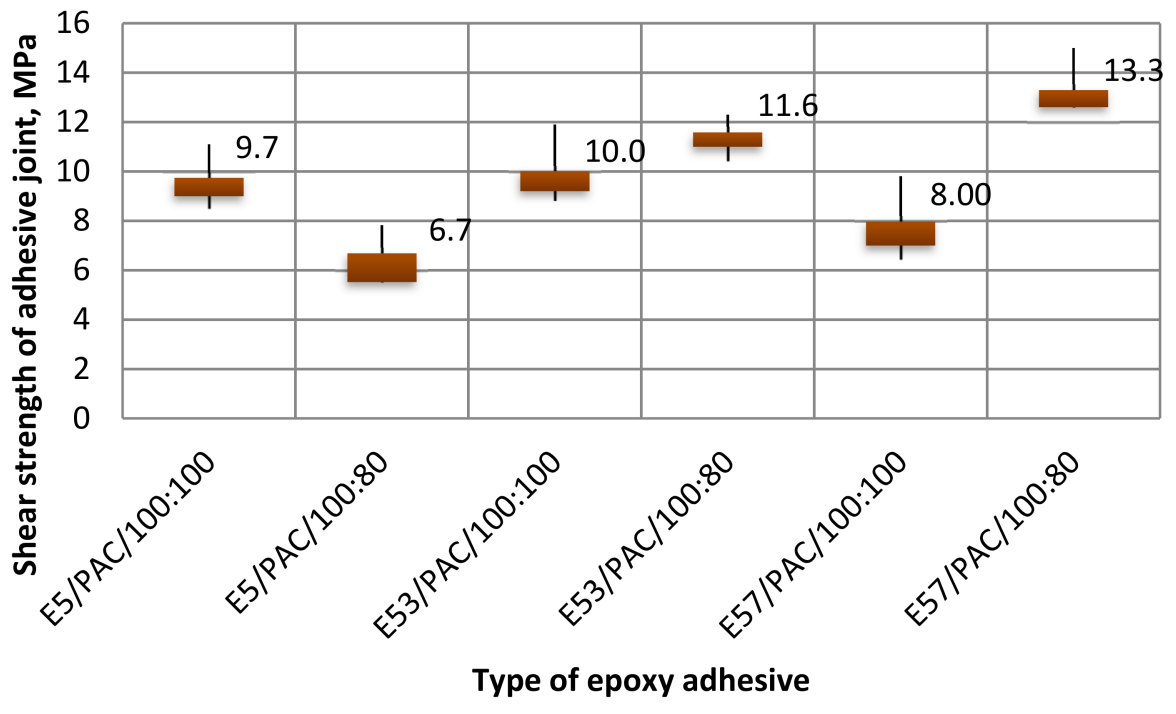

Figure 13. Shear strength of adhesive joints made with various types of epoxy adhesives.

With regard to the adhesives containing the modified epoxy resins (Epidian 53 and Epidian 57), it was noted that a higher curing agent content (above the recommended stoichiometric values) contributes to the reduction in the shear strength of adhesive joints, respectively in the case of E53/PAC/100:80 epoxy adhesive versus E53/PAC/100:100 epoxy adhesive by $14 \%$, and in the case of E57/PAC/100:80 epoxy adhesive versus E57/PAC/100:100 epoxy adhesive by 39\%.

Hence, it is not recommended to use larger amounts of curing agent in the adhesive (above the recommended stoichiometric values), as it reduces the strength of adhesive joints made with such adhesives.

Comparing the shear strength of adhesive joints made with epoxy adhesive comprising Epidian 5 base epoxy resin, containing two amounts of curing agent, but within the recommended stoichiometric amounts of resin and curing agent, it was noticed that a lower amount of curing agent in the epoxy adhesive contributed to lower joint strength. The strength of the adhesive joint made with E5/PAC/100:80 epoxy adhesive is $6.69 \mathrm{MPa}$, which is $60 \%$ of the strength of the adhesive joint made with E5/PAC/100:100 epoxy adhesive.

The elongation at break of adhesive joints (mean value with standard deviation), depending on the epoxy adhesive used, is shown in Figure 14.

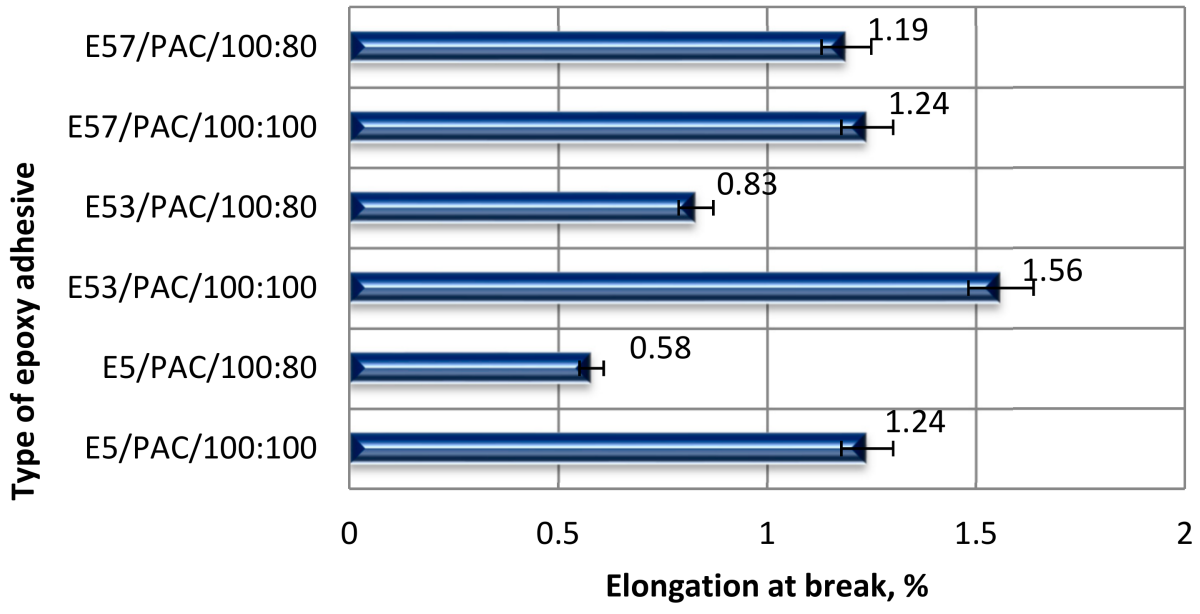

Figure 14. Elongation at break of adhesives joints. 
The obtained results (Figure 14) show that the higher elongation at break value is characteristic for the adhesive joints made with adhesives with a higher curing agent content in the adhesive composition (i.e., the ratio of resin and curing agent in the epoxy adhesive is 1:1). In the case of E53/PAC/100:100 and E57/PAC/100:100 epoxy adhesives, they contain an additive curing agent above the recommended amount of stoichiometric ratio resin/curing agent. A slight elongation at break difference was observed in the case of using epoxy adhesive based on the Epidian 57 epoxy resin. It can be seen that in the case of all analyzed adhesives, a greater amount of curing agent contributes to a greater elongation of the adhesive joint.

\section{Discussion}

\subsection{Mechanical Properties of Epoxy Adhesives}

The obtained test results showed that epoxy adhesives based on modified epoxy resins (Epidian 53 and Epidian 57), containing amounts of polyamide curing agent above the recommended stoichiometric ratio of epoxy resin/curing agent, show worse strength properties than epoxy adhesives containing the maximum recommended stoichiometric ratio. In the case of the epoxy adhesive containing Epidian 5 epoxy resin and a lower amount of polyamide curing agent, but within the recommended range, significantly greater compressive strength was achieved compared to the adhesive with a higher curing agent content (E5/PAC/100:100). Rudawska at al. [33] reported the results of research on e.g., tensile strength of adhesive compositions containing two types of epoxy resin: Epidian 5 and Epidian 6, and two types of polyamide curing agents. The resins and curing agents were mixed in different stoichiometric ratios. It was found that in most cases the use of lower curing agent content results in a higher tensile strength of a given adhesive composition. Although in this work the compressive strength was analyzed, a similar relationship can be observed for the epoxy adhesive containing Epidian 5 epoxy resin.

The use of the amount of curing agent in the range of stoichiometric ratio allows to obtain slightly different properties, as often not only one parameter is considered, but several parameters, and specific properties are selected. In some cases, the choice of adhesive is determined by the flexibility of the adhesive, which is required for certain applications.

Many authors indicate that the properties of epoxy resin/curing agent system depend on the type of curing agent $[2,6,7,25,42]$ as well as the stoichiometric ratio of epoxy resin and curing agent $[28,34]$. The type of epoxy resin is also no less important $[21,32,33]$. The results obtained in this work are in good agreement with whose obtained for example by Liu et al. [19], Saleh et al. [25] and also Amin et al. [36]. They presented that the type of curing agent has a direct effect on the flexural strength and by using various types of curing agents. d'Almeida and Monteiro [26] underlined that e.g., the deformation behavior in compression of the DGEBA/TETA epoxy system cured at room temperature without any post cure treatment, is strongly dependent on the epoxy resin/curing agent ratio. The results obtained in this study also confirm these conclusions, although in the conducted experimental studies, additionally modified epoxy resins and polyamide curing agent were used. The results confirm the general trend of dependencies presented by other scientists.

The greatest deformation occurred for E57/PAC/100:100 adhesive samples, and the smallest for E5/PAC/100:100 adhesive. For E57/PAC/100:80 epoxy adhesive, the reduction of the curing content in the adhesive mass to 100:80 results in a several-fold reduction in sample deformation. The situation is different for E5/PAC/100:100 and E53/PAC/100:100 epoxy adhesives, for which the deformation is three or four times smaller when using the 100:100 ratio. Polymers may show brittle or ductile behavior in strength tests. These properties can be initially assessed on the basis of the recorded sample figures from tensile tests. A characteristic feature of brittle materials is small strain at failure value, generally $\leq 5 \%$. The curves shown in Figures 6-11 represent ductile materials, although not typical for purely plastic materials (lots of thermoplastic materials shows the strain at failure value of $50-1000 \%$, which qualifies them to be ductile or very ductile). With row extensions a 
dozen or so percent of ductility is rather moderate. Ductility is an important feature of the materials used in for example the production of packaging, because it is a measure of impact resistance.

d'Almeida and Monteiro [26] presented e.g., that for the phr ratios equal and above the stoichiometric point, phr 113, the epoxy systems (epoxy resin based on bisphenol A (DGEBA) and the triethylenetetramine (TETA) present a large range of deformation capacity. Moreover, according to these authors, the systems with higher phr ratios not only have higher deformability but also a higher degree of cure. This apparently implies that the epoxies with a more crosslinked macromolecular network are more deformable than the more open structures associated with the low phr ratio systems. This is surprising since the opposite trend would be the normally expected result, because a higher degree of cure brings a more rigid structure for a given monomer/hardener system, what as presented, among others at work prepared by Tang and Springer [42]. Therefore, d'Almeida and Monteiro [26] underlined that varying the epoxy resin/curing agent ratio does not only change the extent of the amine-epoxy resin reaction but also changes a deformation controlling structural parameter.

The considered results depend on also the applied polyamide curing agent (PAC trade name). The main advantage of which is the increase in flexibility and impact strength of the adhesive, compared to other types of curing agents (e.g., triethylenetetramine). Therefore, its use is recommended in the case of joining elements or making cured epoxy elements, susceptible to deformation. Moreover, it was noticed that the obtained results are also influenced by the type of resin used as a component of the adhesive with the same type of curing agent.

\subsection{Mechanical Properties of Adhesive Joints}

In the case of E53/PAC/100:80 and E57/PAC/100:80 epoxy adhesives, greater strength of adhesive joints can be noticed, if the epoxy adhesive contained the highest values of polyamide curing agent, but within the range of recommended stoichiometric ratios. It should be noted that the mentioned curing agent values in epoxy adhesives were the highest of the recommended stoichiometric ratios of resin and curing agent (i.e., 100: 80). It can therefore be assumed that in the case of epoxy adhesives in the case of epoxy adhesives based on modified epoxy resins (Epidian 53 and Epidian 57) and containing the polyamide curing agent above the recommended stoichiometric ratio (100 g resin/ $100 \mathrm{~g}$ curing agent), it is not recommended to use larger amounts of curing agent in the adhesive, because the strength of the adhesive joints made with the use of such adhesives decreases. However, this requires further research, especially with regard to adhesives containing unmodified epoxy resins.

Referring to the results presented in [33], related to the determination of elongation at break in tensile strength tests for an adhesive composition containing Epidian 5 epoxy resin and polyamide curing agent (PAC trade name), it was noticed that among the adhesive compositions Epidian 5/PAC, the highest elongation was obtained for Epidian 5/PAC/100:80 - the lowest amount of curing agent and the lowest for the epoxy adhesive containing the largest (tested) amount of curing agent, $100 \mathrm{~g}$ per $100 \mathrm{~g}$ epoxy resin. The difference between elongations was $40 \%$. It should be noted that the above-mentioned curing agent values were adopted within the recommended curing agent values per $100 \mathrm{~g}$ of resin (within the stoichiometric ratio of resin/curing agent).

It can be also noticed that the higher elongation at break value is characteristic for the adhesive joints made with adhesives with a higher curing agent content in the adhesive composition, i.e., 1:1 (100:100) ratio of epoxy resin and curing agent.

With regard to the obtained results of the adhesive joints strength and the adhesive layer thickness, it is also worth noting that adhesive joints with a smaller thickness of the adhesive layer were characterized by higher strength and this applies to all types of epoxy adhesive. 
The correlation coefficient between the values of these analyzed quantities is 1, which means that there is a strong correlation (dependence) between the strength of the adhesive joints and the thickness of the adhesive joint. This coefficient (Pearson's linear correlation coefficient) is positive, which means that there is a linear relationship between the random variables, with the increase of one variable, the value of the other variable also increases.

This confirms the relationships presented in the literature by da Silva at al. [43], Crocombe [44], Zhu and Kedward [45] or Taib et al. [46] and Kahraman et al. [47], Rudawska [48] and Davies at al. [49] related to the dependence of the adhesive layer (bondline) thickness and the strength of the adhesive joints. Liao et al. [39] underlined that for the joint with the ductile adhesive, the ultimate tensile loading increases as the adhesive thickness decreases. Zhu and Kedward [45] revealed that the maximal strength of lap joints of ductile adhesive increased with decreasing adhesive layer thickness. Taib et al. [46] presented that the decreased failure load to increasing bond thickness in terms of the stress state (i.e., plane stress or plane strain) prevailing inside the adhesive layer: the thin bond thickness favors plane stress while thick bond thickness favors the plane strain state. Kahraman et al. [47] presented the general trend of decrease in single-lap adhesive joints shear strength with adhesive layer thickness.

\subsection{Comparison of Epoxy Adhesive and Adhesive Joints Mechanical Properties}

The comparison of the epoxy adhesive properties and adhesive joints was based on the compressive strength of epoxy adhesive and tensile strength of adhesive joints, taking into account criterion C1 (Table 5). This criterion applies to epoxy adhesives containing the highest amounts of polyamide curing agent in the adhesive within the recommended stoichiometric ratio, appropriate for each type of resin (Table 2).

Comparing the compressive strength of epoxy adhesives and the strength of adhesive joints prepared with these adhesives was made based on the Pearson linear correlation coefficient $r$ using the Statistica program (Table 8).

Table 8. Correlation of compressive strength of epoxy adhesive and tensile strength of adhesive joints.

\begin{tabular}{cccc}
\hline Comparative & \multicolumn{3}{c}{ Statistical Parameters } \\
\cline { 2 - 4 } Quantity: $\mathbf{X}^{\mathbf{1}}$ and $\mathbf{Y}^{\mathbf{2}}$ & Mean Values (MPa) & $\mathbf{r}(\mathbf{X}, \mathbf{Y})$ & $\mathbf{R}^{\mathbf{2}}$ \\
\hline E5/PAC/100:100 & 37.8 & 0.71 & 0.51 \\
Rt E5/PAC/100:100 & 9.7 & 0.56 & \multirow{2}{*}{0.31} \\
\hline E53/PAC/100:80 & 56.7 & 0.19 \\
Rt E53/PAC/100:80 & 11.6 & 0.44 & \multirow{2}{*}{} \\
\hline E57/PAC/100:80 & 17.1 & & \\
Rt E57/PAC/100:80 & 13.3 &
\end{tabular}

${ }^{1}$ compressive strength of epoxy adhesive. ${ }^{2}$ tensile strength of adhesive joints (Rt).

The highest Pearson correlation coefficient $(\mathrm{r}(\mathrm{X}, \mathrm{Y}))$ determined for the analyzed cases was approximately 0.71 and this implies a fairly strong relationship between the compressive strength of E5/PAC/100:100 epoxy adhesive and tensile strength of adhesive joints made by E5/PAC/100:100 epoxy adhesive. In other cases, the correction coefficient is smaller, which means a smaller dependence between the analyzed quantities for compressive strength of E53/PAC/100:80 epoxy adhesive and adhesive joints prepared by this adhesive and for compressive strength of E57/PAC/100:80 epoxy adhesives and adhesive joints prepared by this adhesive. The coefficient of determination, $R^{2}$ was $0.19-0.51$ which meant that the adhesive joint strength could not be explained by changes in each of the compressive strength of epoxy adhesive considered.

In further planned tests, additional tensile and bending strength tests of epoxy adhesives and an attempt to determine the correlation of the strength results with the strength of adhesive joints are foreseen. 


\section{Conclusions}

The presented tests concerned the determination of the effect of the type of adhesive on the compressive strength and compressive strain of epoxy adhesives and the shear strength of the adhesive joints of steel sheets made of the adhesives analyzed in the first stage. On the basis of the obtained results of tests of epoxy adhesives, it can be concluded that:

- In the case of E53/PAC/100:80 and E57/PAC/100:80 epoxy adhesives, which contained the highest amount of curing agent content in the recommended stoichiometric ratios, a higher value of compressive strength was obtained in comparison to these epoxy adhesives, but containing a polyamide curing agent above the recommended stoichiometric ratio (100:100);

- The compressive strength of the epoxy adhesive containing the unmodified resin (Epidian 5) in the range of the recommended stoichiometric ratios epoxy resin/curing agent, the epoxy adhesive with a lower amount of polyamide curing agent (E5/PAC/ 100:80) is characterized by higher compressive strength than a epoxy adhesive with a higher amount of curing agent (maximum amount of curing agent from the recommended stoichiometric values).

- Taking into account the compressive strength analysis, the shape of the stress-strain curve and the fact that none of the samples was completely damaged, it can be concluded that the tested adhesives are materials of reduced stiffness, exhibiting some of the characteristics of ductile materials;

- The type of adhesive used and the amount of curing agent had a significant influence on the shear strength of the adhesive joints;

- The highest shear strength of adhesive joint was that of the joints with the use of an adhesive containing the highest of the recommended ranges of stoichiometric ratios of resin and curing agent (among the analyzed adhesives);

- In the case of adhesives prepared on the basis of modified epoxy resins (Epidian 53 and Epidian 57) containing a polyamide curing agent, it is not recommended to use larger amounts of curing agent in the epoxy adhesive (above the recommended stoichiometric values), because the strength of the adhesive joints made with such adhesives decreases.

Summing up, it was noticed that both the type of resin and the amount of curing agent in the epoxy adhesive and also stoichiometric ratio have a significant impact both on the mechanical properties of the epoxy adhesive itself and on the strength of adhesive joints made with the analyzed types of adhesives. For this reason, it is necessary to analyze both the strength requirements of the adhesive itself and the adhesive joints, which will allow for the best selection of the type of adhesive in order to obtain the desired strength and ductile, depending on the application.

Funding: This research received no external funding.

Data Availability Statement: Data sharing not applicable.

Acknowledgments: Faculty of Mechanical Engineering, Lublin University of Technology, Lublin, Poland.

Conflicts of Interest: The author declares no conflict of interest.

\section{References}

1. Brockmann, W.; Geiß, P.L.; Klingen, J.; Schröder, B.; Gei, P.L.; Klingen, J.; Schrder, B. Adhesive Bonding; Wiley: Hoboken, NJ, USA, 2008; pp. 205-369.

2. Lee, H.L.; Neville, H. Handbook of Epoxy Resins; McGraw-Hill: New York, NY, USA, 1988.

3. Prolongo, S.G.; del Rosario, G.; Ureña, A. Comparative study on the adhesive properties of different epoxy resins. Int. J. Adhes. Adhes. 2006, 26, 125-132. [CrossRef]

4. Suárez, J.C.; Diez de Ulzúrrun, I.; Biezma, M.V.; Ruiz Román, J.M.; Martínez, M.A.; del Real, J.C.; López, F. Case studies in adhesives selection. J. Mat. Process Technol. 2003, 143-144, 219-224. [CrossRef]

5. Adams, R.D. Adhesive Bonding; Elsevier: Amsterdam, The Netherlands, 2005; pp. 257-525. 
6. Czub, P.; Bończa-Tomaszewski, Z.; Penczek, P.; Pielichowski, J. Chemistry and Technology of Epoxy Resins; WNT: Warsaw, Poland, 2002. (In Polish)

7. May, C.A. Epoxy Resins, Chemistry and Technology, 2nd ed.; Marcel Dekker: New York, NY, USA, 1988; pp. 9-20, 465-485, 653-670.

8. Higgins, A. Adhesive bonding of aircraft structures. Int. J. Adhes. Adhes. 2000, 20, 367-376. [CrossRef]

9. Yoon, I.-N.; Lee, Y.; Kang, D.; Min, J.; Won, J.; Kim, M.; Kang, Y.S.; Kim, S.-H.; Kim, J.-J. Modification of hydrogenated Bisphenol A epoxy adhesives using nanomaterials. Int. J. Adhes. Adhes. 2011, 31, 119-125. [CrossRef]

10. Nakamae, K.; Nishino, T.; Airu, X.; Asaoka, S. Localization of the curing agent at an epoxy resin/oxidized aluminium interface. Int. J. Adhes. Adhes. 1995, 15, 15-20. [CrossRef]

11. Saba, N.; Jawaid, M.; Alothman, O.Y.; Paridah, M.; Hassan, A. Recent advances in epoxy resin, natural fiber-reinforced epoxy composites and their applications. J. Reinf. Plast. Compos. 2016, 35, 447-470. [CrossRef]

12. Penn, L.S.; Wang, H. Epoxy Resins. In Handbook of Composites; Springer International Publishing: Berlin/Heidelberg, Germany, 1998; pp. 48-74.

13. Rudawska, A. Epoxy adhesives. In Handbook of Adhesive Technology; Pizzi, A., Mittal, K.Z., Eds.; CRS Press Taylor \& Frances Group: Boca Raton, FL, USA, 2018; pp. 415-442.

14. Gladkikh, S.N.; Kolobova, V.M.; Kuznetsova, L.I. Fast-curing adhesive compositions based on modified epoxy resins. Polym. Sci. Ser. C 2007, 49, 193-194. [CrossRef]

15. Czub, P.; Franek, I. Epoxy resins modified with palm oil derivatives_Preparation and properties. Polimery 2013, 58, 135-139. [CrossRef]

16. Czaderski, C.; Martinelli, E.; Michels, J.; Motavalli, M. Effect of curing conditions on strength development in an epoxy resin for structural strengthening. Compos. Part B Eng. 2012, 43, 398-410. [CrossRef]

17. Rudawska, A.; Czarnota, M. Selected aspects of epoxy adhesive compositions curing process. J. Adhes. Sci. Technol. 2013, 27, 1933-1950. [CrossRef]

18. Moussa, O.; Vassilopulos, A.P.; Keller, T. Effects of low-temperature curing on physical behaviour of cold-curing epoxy adhesives in bridge construction. Int. J. Adhes. Adhes. 2012, 32, 15-22. [CrossRef]

19. Liu, Z.S.; Erhan, S.Z.; Calvert, P.D. Solid freeform fabrication of epoxidized soybean oil/epoxy composite with bis or polyalkyleneamine curing agents. Comp. A 2007, 38, 87-93. [CrossRef]

20. Ozgul, E.O.; Ozkul, M.H. Effects of epoxy, hardener, and diluent types on the hardened state properties of epoxy mortars. Constr. Build. Mater. 2018, 187, 360-370. [CrossRef]

21. Pertie, E.M. Epoxy Adhesive Formulation; McGraw-Hill: New York, NY, USA, 2006; pp. 3-19, 26-41, 43-53, 71-82, 85-98, 207-225, 229-236.

22. Khoee, S.; Hassani, N. Adhesion strength improvement of epoxy resin reinforced with nanoelastomeric copolymer. Mater. Sci. Eng. A 2010, 527, 6562-6567. [CrossRef]

23. Hartshorn, S.R. Structural Adhesives. In Chemistry and Technology; Plenum Press: New York, NY, USA; London, UK, 1986; pp. 134-166.

24. Tomuta, A.; Ferrando, F.; Serra, À.; Ramis, X. New aromatic-aliphatic hyperbranched polyesters with vinylic end groups of different length as modifiers of epoxy/anhydride thermosets. React. Funct. Polym. 2012, 72, 556-563. [CrossRef]

25. Saleh, N.J.; AbdulRazak, A.A.; Tooma, M.A.; Aziz, M.E. A study mechanical properties of epoxy resin cured at constant curing time and temperature with different hardeners. Eng. Tech. J. 2011, 29, 1804-1818.

26. D'Almeida, J.; Monteiro, S. The Role of the Resin Matrix/Hardener Ratio on the Mechanical Properties of Low Volume Fraction Epoxy Composites. Adv. Perform. Mater. 1997, 4, 285-295. [CrossRef]

27. Vanlandingham, M.R.; Eduljee, R.F.; Gillespie, J.W., Jr. Relationships between stoichiometry, microstructure, and properties for amine-cured epoxies. J. Appl. Polym. Sci. 1999, 71, 699-712. [CrossRef]

28. D'Almeida, J.; Monteiro, S. The effect of the resin/hardener ratio on the compressive behavior of an epoxy system. Polym. Test. 1996, 15, 329-339. [CrossRef]

29. Garcia, F.G.; Leyva, M.E.; De Queiroz, A.A.A.; Simões, A.Z. Durability of adhesives based on different epoxy/aliphatic amine networks. Int. J. Adhes. Adhes. 2011, 31, 177-181. [CrossRef]

30. Xu, M.Z.; Jia, K.; Liu, X.B. Effect of bisphenol-A on the structures and properties of phthalonitrile-based resin containing benzoxazine. Express Polym. Lett. 2015, 9, 567-581. [CrossRef]

31. Ham, Y.R.; Lee, D.H.; Kim, S.H.; Shin, Y.J.; Yang, M.; Shin, J.S. Microencapsulation of imidazole curing agent for epoxy resin. J. Ind. Eng. Chem. 2010, 16, 728-733. [CrossRef]

32. Rudawska, A. The influence of curing conditions on the strength of adhesive joints. J. Adhes. 2020, 96, 402-422. [CrossRef]

33. Rudawska, A.; Worzakowska, M.; Bociaga, E.; Olewnik-Kruszkowska, E. Investigation of selected properties of adhesive compositions based on epoxy resins. Int. J. Adhes. Adhes. 2019, 92, 23-36. [CrossRef]

34. D'Almeida, J.R.M.; Monteiro, S.N. The influence of the amount of hardener on the tensile mechanical behavior of an epoxy system. Polym. Adv. Technol. 1998, 9, 216-221. [CrossRef]

35. Bockenheimer, C.; Valeske, B.; Possart, W. Network structure in epoxy aluminium bonds after mechanical treatment. Int. J. Adhes. Adhes. 2002, 22, 349-356. [CrossRef]

36. Amin, K.G.; Patel, K.J.; Patel, R.G. Curing Kinetics, Thermal Stability and the Glass Fibre Reinforced Composites of Novel Tetrafunctional Epoxy Resin. Int. J. Polym. Mater. 1999, 43, 127-136. [CrossRef] 
37. Rudawska, A.; Wahab, M.A.; Müller, M. Effect of ageing process on mechanical properties of adhesive tubular butt joints in aqueous environment. Int. J. Adhes. Adhes. 2020, 96, 102466. [CrossRef]

38. Rudawska, A. Surface Treatment in Bonding Technology; Elsevier BV: Amsterdam, The Netherlands, 2019 ; pp. 13-47.

39. Liao, L.; Huang, C.; Sawa, T. Effect of adhesive thickness, adhesive type and scarf angle on the mechanical properties of scarf adhesive joints. Int. J. Solids Struct. 2013, 50, 4333-4340. [CrossRef]

40. Epoxy Resin Folders. CIECH-Sarzyna. Available online: http://www.ciechzywice.pl/pl/produkty/chemia-organiczna/zywice/ zywice-epoksydowe (accessed on 12 January 2021).

41. Rudawska, A.; Araźna, M. Strength and deformability of selected epoxy compositions, including tests of lap joints of steel sheets. Plast Process 2017, 2, 134-143. (In Polish)

42. Tang, J.; Springer, G.S. Effects of Cure and Moisture on the Properties of Fiberite 976 Resin. J. Compos. Mater. 1988, $22,2-14$. [CrossRef]

43. Da Silva, L.F.; Carbas, R.; Critchlow, G.W.; Figueiredo, M.; Brown, K. Effect of material, geometry, surface treatment and environment on the shear strength of single lap joints. Int. J. Adhes. Adhes. 2009, 29, 621-632. [CrossRef]

44. Crocombe, A. Global yielding as a failure criterion for bonded joints. Int. J. Adhes. Adhes. 1989, 9, 145-153. [CrossRef]

45. Zhu, Y.; Kedward, K. Methods of Analysis and Failure Predictions for Adhesively Bonded Joints of Uniform and Variable Bondline Thicknessn; U.S. Department of Transportation: Washington, DC, USA, 2005.

46. Taib, A.A.; Boukhili, R.; Achiou, S.; Gordon, S.; Boukehili, H. Bonded joints with composite adherends. Part I. Effect of specimen configuration, adhesive thickness, spew fillet and adherend stiffness on fracture. Int. J. Adhes. Adhes. 2006, 26, 226-236. [CrossRef]

47. Kahraman, R.; Sunar, M.; Yilbas, B. Influence of adhesive thickness and filler content on the mechanical performance of aluminum single-lap joints bonded with aluminum powder filled epoxy adhesive. J. Mater. Process. Technol. 2008, 205, 183-189. [CrossRef]

48. Rudawska, A. Influence of the thickness of joined elements on lap length of alluminium alloy sheet bonded joints. Adv. Sci. Technol. Res. J. 2015, 9, 35-44. [CrossRef]

49. Davies, P.; Sohier, L.; Cognard, J.-Y.; Bourmaud, A.; Choqueuse, D.; Rinnert, E.; Créac'hcadec, R. Influence of adhesive bond line thickness on joint strength. Int. J. Adhes. Adhes. 2009, 29, 724-736. [CrossRef] 